\title{
RESEÑA: EL TEATRO HISTÓRICO DE DACIA MARAINI: “VERÓNICA FRANCO, MERETRIZ Y ESCRITORA” E "HISTORIA DE ISABELLA MORRA RELATADA POR BENEDETTO CROCE”. MILAGRO MARTÍN CLAVIJO (EDICIÓN, INTRODUCCIÓN Y TRADUCCIÓN) ${ }^{1}$
}

\begin{abstract}
Angelo Azzilonna ${ }^{2}$
Milagro Martín Clavijo (edición, introducción y traducción). El teatro histórico de Dacia Maraini: "Verónica Franco, Meretriz y escritora” e "Historia de Isabella Morra relatada por Benedetto Croce”. Madrid: Dykinson, 2019. ISBN: 978-84-1324479-2.

El teatro histórico de Dacia Maraini: Verónica Franco, meretriz y escritora e Historia de Isabella di Morra relatada por Benedetto Croce es una novedosa edición crítica de la experta profesora italianista Milagro Martín Clavijo, basada en un interesante estudio, realizado en el ámbito del Proyecto de Investigación “Ausencia II”, coordinado por la catedrática Mercedes Arriaga Flórez cuya amplia trayectoria académica aborda escritoras italianas inéditas en la querella de las mujeres (FEM 201570182-P).

El volumen, publicado por la Editorial madrileña Dykinson, especializada en ciencias sociales y humanidades cuenta con una exhaustiva introducción, fundamental para una adecuada valoración de la vida y de la obra de dos escritoras transalpinas que por distintas razones, representan unos ejemplos que a la vez corroboran y trastocan ciertos cánones literarios que excluían a la mujer de la esfera socio-cultural, víctima de

\footnotetext{
${ }^{1}$ Fecha de recepción: 10/11/2019.

Fecha de aceptación: 10/11/2019.

${ }^{2}$ Doctor en Filología Italiana y miembro del Grupo de Investigación "Escritoras y Personajes Femeninos en la Literatura" de la Universidad de Salamanca, España; $\square$ angeloazzilonna@ hotmail.com.
} 
un arraigado modelo patriarcal, desafortunadamente aún vigente en numerosas y cercanas áreas geográficas.

Uno de los más claros y loables propósitos de la mencionada edición radica en rescatar del olvido por parte de la crítica y dar visibilidad a un público heterogéneo la figura de dos literatas del Renacimiento italiano, merecedoras de atención, bien por sus peculiares vivencias, dentro y fuera de los márgenes tradicionalmente asignados a las mujeres, bien por la calidad artística de su escritura que posee un dúplice valor: ético y estético. En esa óptica se puede entender la certera elección de Milagro Martín Clavijo que en el panorama editorial en español traduce, analiza y profundiza a dos autoras renacentistas italianas, Verónica Franco e Isabella Morra que mediante sus historias personales y su relación con la escritura señalan una voluntad de cambio de paradigmas en la sociedad europea ya en el siglo XVI; se trata de dos artistas poco conocidas en lengua castellana y poco estudiadas incluso en su Italia natal. La estudiosa, además, a lo largo de su edición crítica brinda al lector moderno una serie de interrogantes, ofreciendo implícita y explícitamente unas respuestas reveladoras, a veces hasta incómodas, cuestionando y enriqueciendo el mismo concepto de historiografía, sirviéndose de la inclusión de literatas sui generis. En este sentido se inserta la trascendencia del teatro histórico, uno de los géneros al que se dedica Dacia Maraini, prolífica y finalmente reconocida escritora italiana, ahora también al alcance de lectores hispanófonos gracias al específico ensayo de Milagro Martín Clavijo donde se recupera su producción dramatúrgica, su compromiso social, expresado a través de la sensibilidad femenina, prescindiendo de filtros oficiales, masculinos, predominantes en el proceso de construcción-preservación de la memoria histórica literaria universal. Apostar por introducir e difundir a un público hispanohablante la obra teatral de Dacia Maraini y más concretamente los lazos bio-bibliográficos de escritoras como Verónica 
Franco e Isabella Morra, responde a la voluntad-necesidad en pleno siglo XXI de contribuir a la renovación pedagógica de unos modelos literarios canonizados, excluyentes que demasiado a menudo minimizan o anulan todo tipo de protagonismo a la mujer dotada de talento artístico, ampliando el patrimonio cultural, la didáctica de la literatura, favoreciendo, en definitiva, el desarrollo de sociedades más reflexivas e igualitarias.

Verónica Franco, cortesana y meretriz en la dinámica ciudad de Venecia e Isabella Morra, poetisa "mártir" del arcaico y machista Mediodía italiano del 1500, con sus experiencias y fortunas tan diversas, pero con rasgos comunes, nos permiten colmar, al menos en parte, el vacío existente en los estudios literarios de escritoras y sobre todo ahondar en la búsqueda de mitos y personajes femeninos en la literatura internacional para analizar, desmontar topos y reconstruir otra identidad femenina, haciendo especial hincapié en el peso de la cultura, de la educación y de la escritura.

La edición crítica de Milagro Martín Clavijo de hecho invita a una profunda revisión del canon literario, intentando visibilizar el trabajo teatral de Maraini y de dos autoras inéditas en el contexto español, centrándose en aquellas obras de carácter autobiográfico. Verónica Franco e Isabella Morra son artistas renacentistas que se complementan; ambas favorecen un acercamiento a la literatura desde una perspectiva de género, renovando ítems, mitos y estereotipos sobre lo "femenino".

En su introducción la estudiosa de la Universidad de Salamanca traza el recorrido artístico de la escritora Dacia Maraini, presenta el papel desempeñado por su teatro, poniendo de manifiesto el descuido de la crítica hacia su copiosa producción dramatúrgica, a diferencia de reconocida narrativa, a lo mejor debido a su enfoque y compromiso social, repleto de personajes femeninos y de escabrosas temáticas, donde la 
mujer deja de ser un mero "objeto" para ser un sujeto activo que empieza a manifestar su personalidad y su disconformidad hacia la filosofía patriarcal. De ahí su preferencia por mujeres literatas subversivas, luchadoras con anhelos de libertad, de autodeterminación, de independencia socioeconómica y emocional para adquirir plena conciencia de su posición de marginalidad, denunciándola y en algunos casos superándola mediante una admirable acción política, social e intelectual.

La centralidad de la mujer en el teatro de Maraini, más allá de sus logros finales, ofrece la oportunidad de reflexionar sobre su subalternidad en familia y en la sociedad, estigmatizar su aislamiento, su soledad, sus obstáculos para realizarse como persona, blanco de prejuicios del imperante modelo machista, vigente en distintas latitudes del mundo.

En el teatro de la italiana, forma y contenido viajan en paralelo; en cuanto al estilo se potencia la palabra, cargada de fuerza y expresividad, aliada de la mujer en sus batallas individuales y colectivas, bien evidente en los vibrantes diálogos y monólogos, densos de pathos y mensajes para el espectador, así como cabe destacar un uso del lenguaje creíble, directo, no exento de una sutil y amarga comicidad, desveladora de una hostil realidad. Milagro Martín Clavijo recorre minuciosamente también las influencias y las etapas del teatro de Maraini que tras un comienzo marcado por un interés hacia lo experimental en los años sesenta, deja paso a una idea de teatro combativo, que ocupa las décadas de los setenta y ochenta con creciente empatía hacia las clases más desfavorecidas, in primis hacia las mujeres, para terminar con una tercera fase teatral, desde los años noventa hasta hoy, donde la dramaturga aboga por personajes femeninos atípicos, a menudo injustamente ignorados o excluidos de los estudios literarios que sin embargo pueden ser referente para la mujer actual por actitud, valor, sensibilidad y compromiso social. A esta última etapa pertenecen las dos obras teatrales de Dacia 
Maraini presentadas aquí, cuyas protagonistas con sus diferentes experiencias e ideales, escenificados con un filtro interpretativo moderno, nos permiten relacionar el pasado con el presente, convirtiéndolas, en muchos aspectos en ejemplo atemporal. Una de ellas es Verónica Franco, escritora y cortesana veneciana del siglo XVI que personifica el deseo de emancipación de la mujer, puesto que su profesión le garantiza independencia moral y material, así como una adecuada formación cultural, capaces de imprimir una huella personal singular, otorgándole seguridad, serenidad y desparpajo; de este modo Verónica Franco ha podido y sabido moverse y desenvolverse exitosamente en ambientes considerados masculinos (la corte, los palacios o la calle), conquistando una sorprendente y pionerística libertad con un modus vivendi fuera de la norma y de la normalidad para aquella época.

Milagro Martín pone de relieve el proficuo binomio teatro histórico-mujer, rasgo definitorio de gran parte de la producción artística de Dacia Maraini, tan crucial para indagar tiempos remotos desde una óptica diferente, más femenina, portadora de un nuevo heterogéneo concepto de historia, analizada desde distintos puntos de vista; el teatro de la transalpina incluye y dignifica las vicisitudes de los vencidos, de los humildes que con sus costumbres, con su trabajo, de manera silenciosa y cotidiana forman la llamada "intrahistoria" unamuniana, excluida de todo tipo de antología oficial. Por tanto, uno de los méritos del teatro de Dacia Maraini consiste en proponer al espectador una representación de la historia más plural y Milagro Martín recalca con agudeza su enriquecedor perspectivismo, la centralidad de la figura de la mujer a través de la literatura que con su visión aporta una revisión crítica del pasado.

Otra peculiaridad subyacente en los dramas de Verónica Franco y de Isabella Morra en los que se detiene el ensayo de la filóloga salmantina es la presencia de la ficción que, lejos de contradecir los acontecimientos históricos, imprescindibles puntos 
de partida (basados -como en el caso de Isabella Morra- en fiables reconstrucciones de críticos e historiadores del calibre de Benedetto Croce) los potencian, ya que confieren mayor credibilidad y humanidad a las biografías de las mujeres-artistas; de ahí que se ofrezcan anécdotas, nunca banales, incluso de sus vidas privadas, que encierran ideologías, costumbres, mentalidades para entrar de lleno en la época. Lo real y lo ficcional, la historia y la fantasía, la documentación y la invención se combinan y se completan mutuamente en las pièces de Maraini, donde el público puede penetrar en un verosímil marco histórico-social y conocer las facetas más personales y familiares de los protagonistas, fusionando historia y microhistoria. Milagro Martín destaca nítidamente la finalidad de la producción teatral de Dacia Maraini que aspira a una concienzuda reflexión sobre el significado y la posible tarea del arte: recordar el pasado, englobando también detalles pertenecientes a la esfera privada de sus personajes, principalmente femeninos; sentimientos, deseos, miedos, así como normas, pensamientos, formalismos y protestas, siempre vehiculados por la escritura, representan una manera eficaz para pasar de lo "subjetivo" a lo "objetivo", para reconstruir la memoria individual y colectiva de la mujer y de la sociedad en una determinada época. En lo específico el teatro de la transalpina se sirve del recuerdo y de su fijación intrageneracional de modo que el espectador actual, sumergido en una realidad cada día más hibrida y globalizada pueda reconocer su identidad. De ahí la estrategia del recuerdo de la dramaturga con la presencia de mujeres que evocando sus biografías y sus verdades nos ayudan a reconsiderar el pasado, la historia, creando lazos entre hoy y ayer, mediante la escenificación de vivencias, ideas y anhelos que permiten ir de lo particular a lo universal. Además, en el constante escamotage del recuerdo se atisba la identidad femenina y su consecuente vinculación al contexto socio-cultural, bien por asimilación, 
bien por contraste hacia el mismo, llevando a sus protagonistas a elegir entre la resignación y la rebeldía.

En esta dicotomía se insertan las historias de Isabella Morra y Verónica Franco; ambas exaltan las potencialidades del arte, de la literatura, refugio real e imaginario, refinado antídoto contra una existencia mediocre y monótona a la que estaba abocada la mujer. Ambas evidencian el nexo de causa-efecto que deriva del ineludible determinismo ambiental al que deben enfrentarse y del que se irradian apasionadas consideraciones sobre otras temáticas asociadas a la mujer (el matrimonio, la maternidad, la fidelidad). Milagro Martín interpreta perfectamente también analogías y diferencias entre las dos protagonistas, empleando una serie de parámetros comunes como son la memoria y el espacio físico de referencia con sus respectivas implicaciones, también simbólicas, útiles a la construcción de sus perfiles, de su carácter, de su conducta, de sus debilidades y de sus virtudes.

El tratamiento del espacio en los dos dramas en concreto es indicador de la eventual pertenencia de la mujer al canon literario; de hecho, a lugares abiertos corresponden por asociación e influencia directa una personalidad y una historia "abierta", fuera del tradicional estereotipo que prevé para ella una vida "cerrada", asfíctica y reprimida en un angosto hogar, puesto que siguiendo la organización efectiva y moral de la sociedad patriarcal, es el espacio doméstico su único posible ámbito de expresión, donde demostrar sus cualidades de impecable ama de casa, de madre y mujer, a diferencia del hombre que desempeñaba una intensa y libre vida pública. Este analítico simbolismo queda patente en el teatro de Dacia Maraini y en la edición curada por Milagro Martín. En este sentido es emblemático el "agujero" en el que está relegada y condenada a vivir Isabella Morra, sola, frustrada, aburrida en un pequeño pueblo de Basilicata, ancestral región sureña de Italia que es para ella una suerte de jaula, que 
cohíbe, impide amar y relacionarse libremente con los hombres, debido al férreo concepto de decoro ético, cuyo eje vertebrador es a su vez la honorabilidad con su manía-hipocresía del "aparentar" que se exigía a la mujer. En un panorama de sofocante discriminación los libros y la poesía para Isabella a la que le espera un aún más trágico destino, son auténticos revulsivos, vías de escape, sinónimos de novedad, libertad, creatividad para evadir, al menos de forma temporánea e imaginaria del total y salvaje aislamiento, de las prohibiciones que acata resignada y bajo la estricta vigilancia física y moral de Cesare, el hermano mayor, cínico castigador de todos los "culpables", implicados en la relación epistolar y literaria que descubre entre su hermana y el poeta Diego Sandoval.

Es reseñable el papel catártico y a su manera transgresor de la cultura, de los versos que la joven y desafortunada protagonista lee y escribe, versos que para decirlo con palabras de Milagro Martín "se convierten en una ventana abierta al exterior [...] una realidad potencial que puede sustituir, aunque sea solo mientras dure la lectura o la narración oral, a la que nos rodea" (Introducción p. 44). Si las tristes vicisitudes de Isabella Morra corroboran el canon literario de mujer sumisa, de "rehén" derrotada por su entorno patriarcal, que sin embargo recurre al arte y a la lírica para sublimar sus ansias de vivir y relacionarse con el mundo, la pièce dedicada a Verónica Franco trastoca radicalmente la clásica imagología femenina. La literata y cortesana veneciana, de hecho, ofrece un perfil de mujer atípico que si, por un lado, sigue siendo una madre casada, por otro nunca anula su vida, ni la reduce únicamente al servicio de su marido y de sus hijos; en este sentido el tratamiento del espacio en la obra resulta bastante sugerente y significativo.

Verónica Franco es ante todo una mujer dinámica, moderna que frecuenta lugares insólitos (cortes, palacios, plazas) e independiente, dotada de carisma, capacidad 
decisional y total libertad. Incluso cuando, voluntariamente elije ser meretriz de lujo, preserva su coherencia, su dignidad y su identidad, visto que es ella que maneja a los hombres y lejos de ser un simple objeto de placer, logra entablar con hombres, así como con prestigiosos gobernadores, una relación que implica cuerpo y mente, hasta llegar al enamoramiento. Es una prostituta con ideales, valores y criterios propios que detesta la mentira, también si es beneficiosa para ella que sabe valerse con autoridad y saber estar, con charme y cultura. Alcanza un complicado equilibrio dentro de esta subversión, conquistando atenciones y respeto en las cortes y en la sociedad, gracias a su brillantez intelectual, a su original conducta, a su carácter, donde prima su entereza que la lleva por ejemplo a rechazar ser amante del rey Enrique III, puesto que en ningún momento quiere renunciar a su plena autonomía.

Una vez más, el teatro de Dacia Maraini nos presenta la complejidad y la ejemplaridad del universo femenino mediante la técnica del perspectivismo plural, introduciendo en sus dramas historias con matices desde diferentes ópticas, de modo que el lector-espectador pueda conocer detalladamente el contexto y la personalidad de sus protagonistas, apreciando vínculos y trasgresiones entre el marco histórico-social y cultural y la formación-afirmación de la identidad. Esta última es una de las finalidades del teatro de Maraini cuyas mujeres constituyen un modelo de fuerza, resistencia y creación de espacios propios, reivindicando un "yo femenino" loable, seguro, en el que se aprecia auto-confianza y autonomía respecto al hombre.

Por tanto, esta edición crítica permite conocer dos de los dramas más valiosos e imprescindibles de la autora italiana, referentes para la mujer de todas las épocas con uno de sus mensajes universales: exaltar el papel de la escritura, eje central y esperanzador, útil para combatir y evadir del patriarcado, forjando una personalidad libre, autónoma e independiente. De ahí uno de los méritos de la filóloga española: 
rescatar del descuido de la crítica oficial y oficialista transalpina la obra teatral de Dacia Maraini, su importante legado ético y artístico, sus olvidadas heroínas que con su pluma, su literatura, a menudo autobiográfica, invitan a una más completa y necesaria revisión de la historia y de la historiografía, canónica y “cómodamente” entendidas. 